\title{
Sacrificial structures for deep reactive ion etching of high-aspect ratio kinoform silicon x-ray lenses
}

Stöhr, Frederik; Michael-Lindhard, Jonas; Hübner, Jörg; Jensen, Flemming; Simons, Hugh; Jakobsen, Anders Clemen; Poulsen, Henning Friis; Hansen, Ole

Published in:

Journal of Vacuum Science and Technology. Part B. Microelectronics and Nanometer Structures

Link to article, DOI:

$10.1116 / 1.4931622$

Publication date:

2015

Document Version

Publisher's PDF, also known as Version of record

Link back to DTU Orbit

Citation (APA):

Stöhr, F., Michael-Lindhard, J., Hübner, J., Jensen, F., Simons, H., Jakobsen, A. C., Poulsen, H. F., \& Hansen, O. (2015). Sacrificial structures for deep reactive ion etching of high-aspect ratio kinoform silicon x-ray lenses. Journal of Vacuum Science and Technology. Part B. Microelectronics and Nanometer Structures, 33(6), [062001]. https://doi.org/10.1116/1.4931622

\section{General rights}

Copyright and moral rights for the publications made accessible in the public portal are retained by the authors and/or other copyright owners and it is a condition of accessing publications that users recognise and abide by the legal requirements associated with these rights.

- Users may download and print one copy of any publication from the public portal for the purpose of private study or research.

- You may not further distribute the material or use it for any profit-making activity or commercial gain

- You may freely distribute the URL identifying the publication in the public portal 


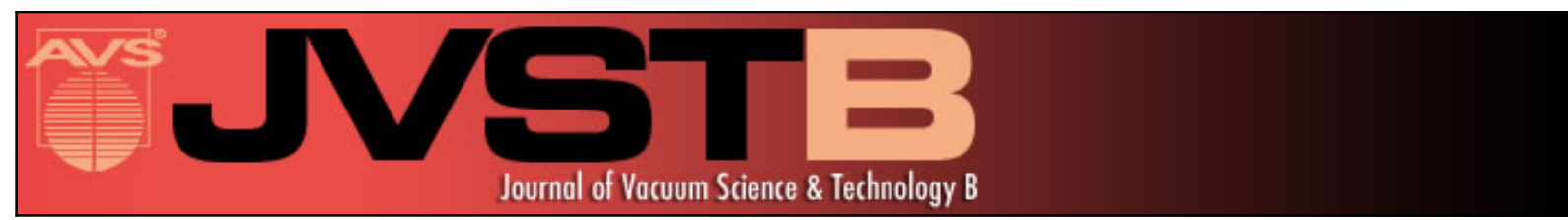

\section{Sacrificial structures for deep reactive ion etching of high-aspect ratio kinoform silicon x-ray lenses}

Frederik Stöhr, Jonas Michael-Lindhard, Jörg Hübner, Flemming Jensen, Hugh Simons, Anders Clemen Jakobsen, Henning Friis Poulsen, and Ole Hansen

Citation: Journal of Vacuum Science \& Technology B 33, 062001 (2015); doi: 10.1116/1.4931622

View online: http://dx.doi.org/10.1116/1.4931622

View Table of Contents: http://scitation.aip.org/content/avs/journal/jvstb/33/6?ver=pdfcov

Published by the AVS: Science \& Technology of Materials, Interfaces, and Processing

\section{Articles you may be interested in}

High aspect ratio $x$-ray waveguide channels fabricated by e-beam lithography and wafer bonding J. Appl. Phys. 115, 214305 (2014); 10.1063/1.4881495

Fabrication of high-aspect ratio silicon nanopillars and nanocones using deep reactive ion etching J. Vac. Sci. Technol. B 27, 2732 (2009); 10.1116/1.3246359

Fabrication of silicon kinoform lenses for hard x-ray focusing by electron beam lithography and deep reactive ion etching

J. Vac. Sci. Technol. B 26, 122 (2008); 10.1116/1.2825167

Optimized fabrication of silicon nanofocusing $x$-ray lenses using deep reactive ion etching J. Vac. Sci. Technol. B 25, 1626 (2007); 10.1116/1.2769361

Single-mask, three-dimensional microfabrication of high-aspect-ratio structures in bulk silicon using reactive ion etching lag and sacrificial oxidation

Appl. Phys. Lett. 85, 6281 (2004); 10.1063/1.1834720

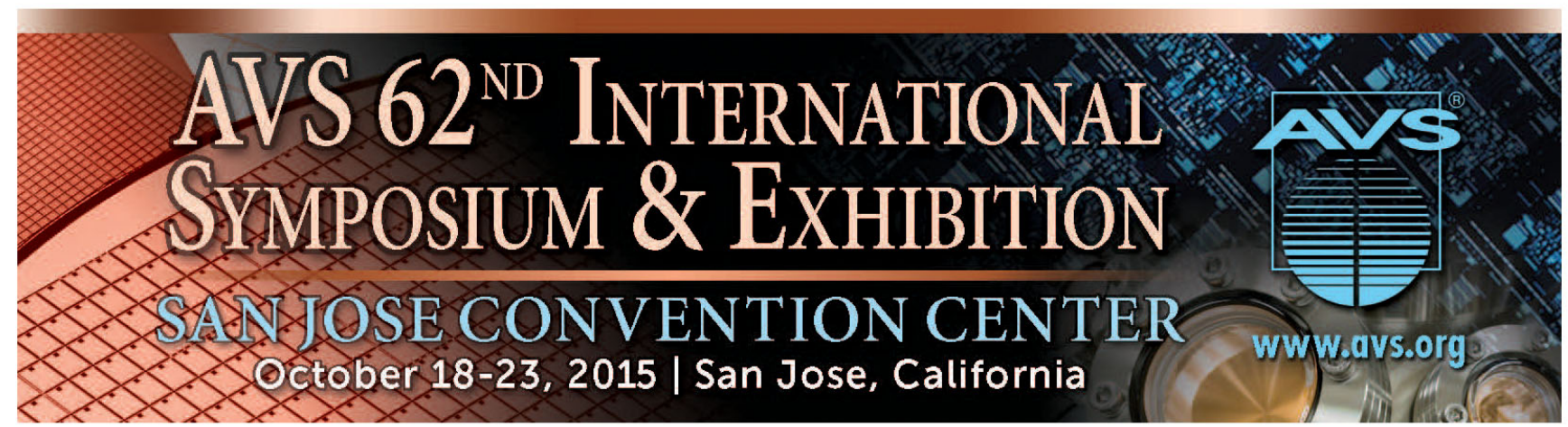




\title{
Sacrificial structures for deep reactive ion etching of high-aspect ratio kinoform silicon x-ray lenses
}

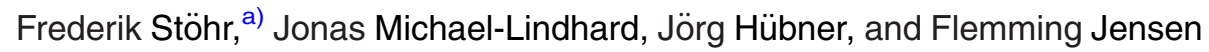 \\ DTU Danchip, Technical University of Denmark, Kongens Lyngby DK-2800, Denmark \\ Hugh Simons, Anders Clemen Jakobsen, and Henning Friis Poulsen
Department of Physics, Technical University of Denmark, Kongens Lyngby DK-2800, Denmark \\ Ole Hansen \\ DTU Nanotech and CINF, Technical University of Denmark, Kongens Lyngby DK-2800, Denmark
}

(Received 12 August 2015; accepted 10 September 2015; published 23 September 2015)

\begin{abstract}
This article describes the realization of complex high-aspect ratio silicon structures with feature dimensions from $100 \mu \mathrm{m}$ to $100 \mathrm{~nm}$ by deep reactive ion etching using the Bosch process. As the exact shape of the sidewall profiles can be crucial for the proper functioning of a device, the authors investigated how sacrificial structures in the form of guarding walls and pillars may be utilized to facilitate accurate control of the etch profile. Unlike other sacrificial structuring approaches, no silicon-on-insulator substrates or multiple lithography steps are required. In addition, the safe removal of the sacrificial structures was accomplished by thermal oxidation and subsequent selective wet etching. The effects of the dimensions and relative placement of sacrificial walls and pillars on the etching result were determined through systematic experiments. The authors applied this process for exact sidewall control in the manufacture of $x$-ray lenses that are very sensitive to sidewall shape nonuniformities. Compound kinoform lenses for focusing hard x-rays with structure heights of $200 \mu \mathrm{m}$ were manufactured, and the lenses were tested in terms of their focusing ability and refracting qualities using synchrotron radiation at a photon energy of $17 \mathrm{keV}$. A $180 \mu \mathrm{m}$ long line focus with a waist of $430 \mathrm{~nm}$ at a focal length of $215 \mathrm{~mm}$ was obtained. (C) 2015 American Vacuum Society. [http://dx.doi.org/10.1116/1.4931622]
\end{abstract}

\section{INTRODUCTION}

Deep reactive ion etching (DRIE) using the Bosch process is an indispensable technique for high-aspect ratio structuring in the MEMS industry. ${ }^{1-3}$ It is a cyclic process, where ion-stimulated directional plasma etching alternates with isotropic deposition of a passivation layer. In every cycle, a passivation layer temporarily protects the sidewalls of structures that have been etched in preceding steps from being etched in a succeeding step. During the etch phase, accelerated ionic species primarily attack horizontal areas, thereby removing the bottom passivation layer and assisting etching of the newly exposed silicon. The sidewall protection layer is partially consumed, but remains intact until it is renewed in a following cycle. If critical parameters such as reactor pressure, gas flows, RF powers, and timing are properly balanced, it is possible to anisotropically structure silicon wafers with near-vertical sidewalls and only minor roughness in the form of scallops originating from the cyclic process.

However, departures from this ideal process occur. ${ }^{2,4,5}$ Due to collisions of ions with other species and their thermal motion, accelerated ions are not perfectly collimated toward the substrate. Instead, they have a finite ion angular distribution (IAD) as illustrated in Fig. 1(a). ${ }^{6,7}$ Moreover, as ions enter trenches or holes, ion deflection (ID) toward the sidewalls occurs ${ }^{8-10}$ e.g., by the attraction of ions by their image charges. ${ }^{11}$ An uncollimated ion bombardment

$\overline{{ }^{a)} \text { Electronic mail: frsto@danchip.dtu.dk }}$ promotes ion/wall collisions, resulting in local sputtering of the passivation layer, partial protection breakthrough, a finite lateral etch rate, and nonvertical sidewalls. Sidewalls of large trenches are usually negatively tapered, i.e., they have a sidewall angle $\alpha<90^{\circ}$ [cf. Fig. 1(a)] since they are exposed to the full IAD independent of the etch depth reached, while narrower trenches show local sidewall features such as barreling or bowing. ${ }^{12-14}$ Depending on the ratio between the width and the depth of a structure, substantial fractions of ions may be lost by wall collisions, known as shadowing. ${ }^{15}$ Consequently, the ion flux necessary for bottom passivation removal and ion etch assistance is decreased, ultimately limiting etch rates. This phenomenon is commonly known as the RIE-lag or aspect ratio dependent etching (ARDE). ${ }^{16}$

As the etch depth increases, ion shadowing is more pronounced in narrower trenches, resulting in a larger reduction in etch rate but simultaneously a narrower IAD. Deflection of ions by image charges at opposing sidewalls may balance each other, further favoring profile control. ${ }^{2}$ Hence, if vertical sidewalls are required, it is imperative to define structures by narrow trenches of constant width and to choose a trench width such that (1) the final aspect ratio does not get exceedingly high, (2) the final average etch rate is not reduced too much (e.g., $50 \%$ of the initial etch rate), and (3) surface defects such as vertical striations or local passivation breakthroughs can be avoided by properly tuning of critical process parameters. With today's equipment, it is common to etch trenches with aspect ratios of 20 and rates $>5 \mu \mathrm{m} / \mathrm{min} .{ }^{17}$ 

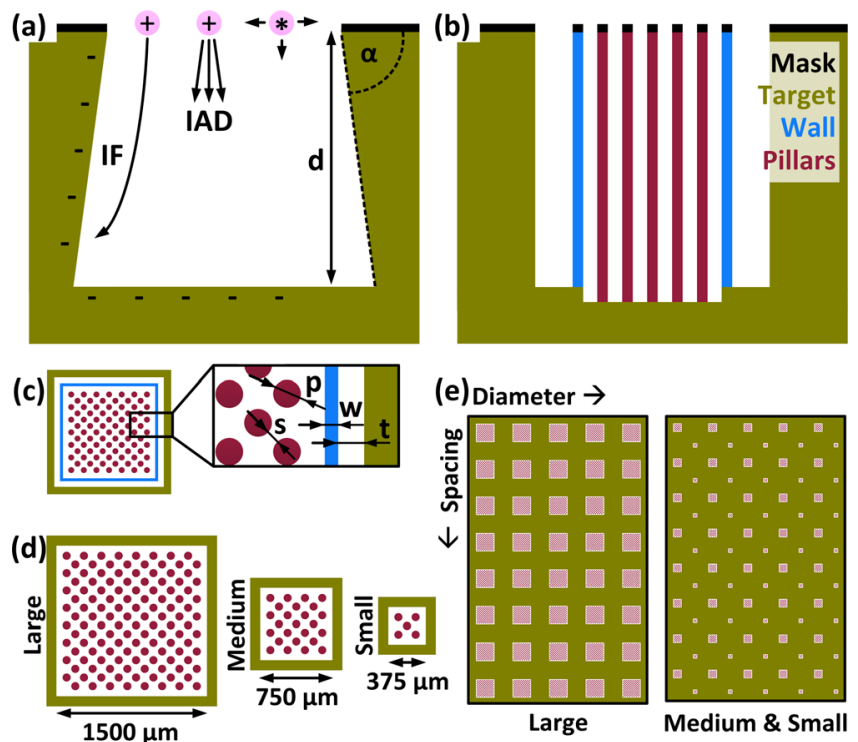

(e) Diameter $\rightarrow$

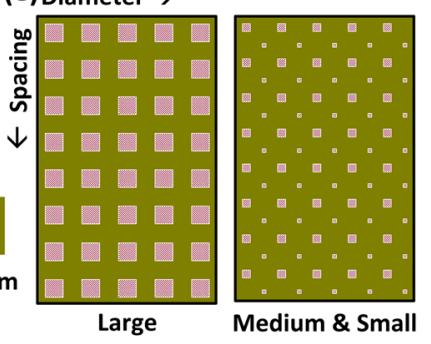

FIG. 1. (Color online) (a) Sidewall angle $\alpha$ of a wide trench with depth $d$ is largely affected by lateral etching originating from isotropically etching radicals, ionic species having a finite IAD and ID attracting ionic species toward the sidewalls. (b) Dividing a wide trench into smaller subunits facilitates anisotropic etching and vertical sidewalls. (c) Micropattern under investigation in this study. The perimeter of target structures is defined by a trench of constant width $t$. The trench is confined by a guarding wall with thickness $w$ and the remaining space within the structure is uniformly filled with dots (or pillars) with diameter $p$ and average spacing $s$. Fields with varying $p$ and $s$ were designed in three different sizes (d) and arranged in grid patterns on the wafer (e)

Often, however, relatively wide or free-standing structures with high-aspect ratios and vertical sidewalls are required. Hence, processes were developed that allow the uniform etching of the perimeters of target structures, while open areas are temporarily filled with sacrificial structures of various shapes. These processes imply multiple process steps, including the removal of the sacrificial structures after shaping the main structures. For example, if permissible, shape-defining trenches may be completely etched through a silicon wafer, releasing material that was completely surrounded by trenches. ${ }^{18-20}$ Wafers may become too fragile for further handling and/or need to be stabilized in an additional process step prior $^{21}$ or subsequent ${ }^{20}$ to throughetching. Alternatively, more expensive silicon-on-insulator substrates combined with notching may be used, which occurs during DRIE once the buried oxide layer is exposed. Sacrificial structures in the shape of, e.g., waffles with narrow segments are undercut and may be removed mechanically $^{22}$ or by plasma etching. ${ }^{23}$ Using single crystalline wafers, the sidewalls of structures may be temporarily protected by thermal oxidation ${ }^{24}$ or reinforced passivation using $\mathrm{C}_{4} \mathrm{~F}_{8},{ }^{25}$ followed by anisotropic etching of the bottom protection and isotropic under-etching of sacrificial silicon. If mechanical removal is impermissible, wide structures may be isotropically etched subsequent to the etching of narrow structures, employing an additional lithography step and a separate masking layer. ${ }^{26,27}$ If structures can be aligned along crystal planes, sacrificial ridges between elementary patterns can be structured by DRIE and removed by anisotropic wet etching, guaranteeing sidewall verticality. $^{28}$

Here, we propose a design and manufacturing strategy necessitating only one lithography step and one plasma etching step. It utilizes narrow sacrificial structures, which are removed by their complete thermal oxidation and selective etching in buffered hydrofluoric acid (bHF). Single crystal wafers can be used and it does not rely on under-etching. Free-standing structures with high-aspect ratios can be realized, while profile control during DRIE is facilitated. The cross sectional design of the sacrificial structures is illustrated in Fig. 1(b), where guarding walls confine trenches that define the perimeter of the target structure, and pillars fill out the remaining space inside the guarding walls.

Figure 1(c) shows a bird's eye view of a square pattern filled with sacrificial structures and highlights the design parameters. The trench width $t$ needs to be chosen according to aforementioned criteria, i.e., such that profile control is enabled and the target etch depth can be reached with reasonable etch rates. The thickness $w$ of the guarding wall and the diameter $p$ of the dots (or pillars) need to be chosen, such that (1) their integrity is guaranteed until the end of the etching and (2) they can be completely thermally oxidized within a reasonable amount of time. Similar to ARDE affecting trenches of variable widths, the mean spacing $s$ between pillars regulates the etch rate and hence needs to be matched to the trench width in order to reach a uniform etch depth of the entire structure.

The present study has two primary goals: first, to explore the capabilities of the proposed design and manufacturing strategy, which involves finding design rules, limitations, and defects, and second to apply this strategy to realize optics for shaping hard x-ray beams.

Refractive lenses are versatile optical components and act, e.g., as condensers in hard x-ray microscopes. ${ }^{29-33}$ Since the material refractive index $n=1-\delta$ is less than unity, focusing lenses for hard $\mathrm{x}$-rays have a concave shape, and since the refractive index decrement $\delta$ is in the order of $10^{-6}$, the lens radius of curvature $R$ is typically in the lower micrometer range. In order to achieve practical focal lengths $(1-1000 \mathrm{~cm})$, multiple lenses may be combined in a compound refractive lens (CRL). To prevent spherical aberration, their shape is typically parabolic as illustrated in Fig. 2(a). Line-focusing lenses were successfully manufactured by lithography and DRIE of silicon. ${ }^{20,31,34-37}$ While planar technology offers great design freedom and precision, silicon lenses are subject to relatively high x-ray absorption, which ultimately limits their effective optical apertures and thus their optical performance. ${ }^{38}$ To overcome this constraint, passive parts of lens material that merely cause absorption and a $2 \pi$ wave front phase shift were removed from the light path to obtain a so-called kinoform lens [cf. Figs. 2(b) and 2(c)]. ${ }^{39-45}$ This kinoform design allows lenses with higher transmittance and higher numerical apertures, hence more efficient optics yielding smaller, more focused beam waists.

The parallelism, i.e., the verticality, and straightness of line-focusing lenses are crucial for their optical performance 

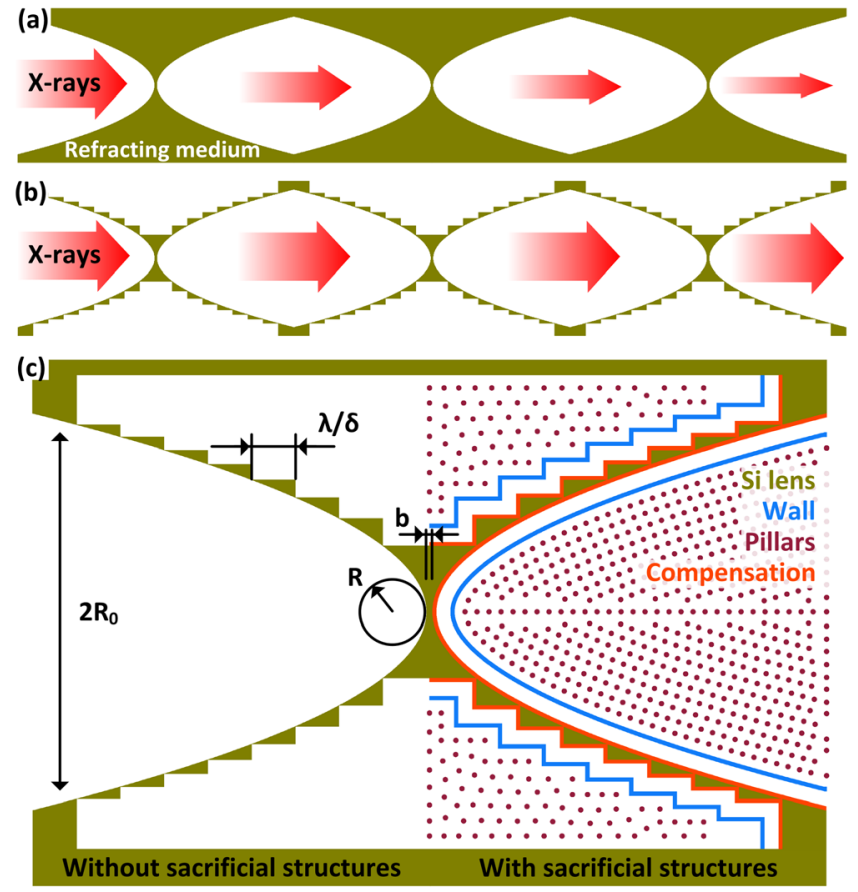

FIG. 2. (Color online) X-ray CRL designs. (a) Standard CRL. (b) Kinoform CRL. Absorbing material merely causing a $2 \pi$ phase shift is removed. (c) Single kinoform lenslet with and without sacrificial structures.

since any sidewall tapering or bowing may cause a deviation from the ideal lens shape and therefore optical aberrations. ${ }^{20}$ Traditionally, lens patterns were etched directly (i.e., without utilizing sacrificial structures), and hence suffered from the aforementioned difficulties during DRIE. Consequently, silicon x-ray lens heights rarely exceeded $100 \mu \mathrm{m}$, and kinoform lenses were prone to failures due to their sharp corners and thin triangular elements. Here, we use sacrificial structures to increase the heights of kinoform lenses and demonstrate their optical performance using synchrotron radiation.

\section{EXPERIMENT}

\section{A. Patterns}

To study the effect of sacrificial structures in detail, two process-development wafer designs and respective lithography masks were used. One design included square patterns with edge lengths of 1500,750 , and $375 \mu \mathrm{m}$ uniformly filled with dots only, hereafter referred to as large, medium, and small fields, respectively. The dots were arranged on square lattices with pitch lengths (or spacing) $s$ [cf. Fig. 1(c)], and $s$ varied from 3 to $10 \mu \mathrm{m}$ in increments of $1 \mu \mathrm{m}$. At the edges of the fields, a distance of $1 \mu \mathrm{m}$ was added to the start of the dot lattice to compensate for locally changing etching conditions. The dot diameter $p$ [cf. Fig. 1(c)] varied in increments of $0.5 \mu \mathrm{m}$ from 3 to $5 \mu \mathrm{m}$ such that complete thermal oxidation of resulting pillars was possible within a reasonable amount of time $(<48 \mathrm{~h})$. Two fields of 60 squares were arranged in a grid as illustrated in Fig. 1(e) with a constant pitch of $1.5 \mathrm{~mm}$ to reduce influences from detrimental effects such as microloading. ${ }^{46-48}$ Additionally, the design contained square patterns with edge lengths of $1500 \mu \mathrm{m}$ that were defined at their perimeters by trenches with varying widths $(t=5,10,15$, and $20 \mu \mathrm{m})$, guarding walls with thicknesses $w(w=3$ and $4 \mu \mathrm{m})$, and $p$-s-combinations deliberately chosen from the squares with dots only. Simple trenches of different widths were also present. The total wafer etch load (i.e., exposed silicon) was $\sim 5 \%$. $^{46}$

The second wafer design included the lens patterns. We chose to design kinoform lenses for an x-ray energy $E=17 \mathrm{keV}$ corresponding to a $2 \pi$ path length $\lambda / \delta=43.7 \mu \mathrm{m}$ [cf. Fig. 2(c), wavelength $\lambda=0.73 \AA, \delta=1.67 \times 10^{-6}$ for silicon]. The CRL was composed of $N=60$ lenslets and had a total length of $49 \mathrm{~mm}$. The radius of curvature $R_{\mathrm{n}}$ and the aperture $2 R_{0, \mathrm{n}}$ of the nth lenslet were adapted to the contraction of the $\mathrm{x}$-ray beam inside the lens, i.e., lenslets were arranged in an adiabatic fashion. ${ }^{49,50}$ The lenslet at the entrance of the CRL was specified by $R_{1}=50 \mu \mathrm{m}$ and $2 \mathrm{R}_{0,1}=400 \mu \mathrm{m}$, while the lenslet at the exit of the CRL was specified by $R_{60}=41 \mu \mathrm{m}$ and $2 R_{0,60}=360 \mu \mathrm{m}$. The bridge thickness $b$ was constantly $6 \mu \mathrm{m}$. Lens patterns including sacrificial structures [cf. Fig. 2(c), $t=15 \mu \mathrm{m}, w=4 \mu \mathrm{m}$, $p=5 \mu \mathrm{m}$, and $s=7 \mu \mathrm{m}]$ were drawn using a code written in MATLAB, including a mesh generator for the uniform placement of dots. ${ }^{51}$ Consumption of silicon, which occurred in the course of thermal oxidation and subsequent selective $\mathrm{SiO}_{2}$ etching for sacrificial structure removal, was compensated for in the design by adding a uniform $3.8 \mu \mathrm{m}$ thick layer around the lens patterns. The total etch load of this wafer was $\sim 7 \%$.

\section{B. Microfabrication}

The starting materials were single side polished, $525 \mu \mathrm{m}$ thick (100) single-crystal silicon wafers with $100 \mathrm{~mm}$ diameters. A thermally grown $750 \mathrm{~nm}$ thick $\mathrm{SiO}_{2}$ film was patterned using standard UV-lithography and reactive ion etching (SPTS, Advanced Oxide Etcher). A bottomanti-reflective coating was applied prior to photo resist spinning, which promoted the adhesion of small dots upon resist development. DRIE using $\mathrm{SF}_{6}$ and $\mathrm{O}_{2}$ during the etching phases and $\mathrm{C}_{4} \mathrm{~F}_{8}$ during the passivation phases was optimized (SPTS, Pegasus). The passivation phase was constantly $1 \mathrm{~s}$, while the etch phase was linearly ramped from 3.2 to $3.4 \mathrm{~s}$ during the $32 \mathrm{~min}$ etching process including 450 cycles. $^{20}$ A platen power of $35 \mathrm{~W}$ was applied during the etch phase only, and the reactor pressure was $\sim 20$ mTorr. Residuals from the passivating layers were ashed (PVA TePla, PS300), and remaining $\mathrm{SiO}_{2}$ was stripped in bHF. Wafers were RCA cleaned for further wet thermal oxidation. A total of $5.6 \mu \mathrm{m} \mathrm{SiO}_{2}$ was grown in five steps $\left(1100{ }^{\circ} \mathrm{C}, 1 \times 16 \mathrm{~h}+4 \times 3 \mathrm{~h}\right)$, each step followed by $\mathrm{SiO}_{2}$ removal in bHF. A total of $2.6 \mu \mathrm{m}$ silicon was consumed, completely removing the sacrificial structures and effectively smoothing the sidewalls. ${ }^{52,53}$ The depth of the square fields was measured using a stylus profilometer (Bruker, Dektak 8), and scanning electron microscopy was performed on a Supra 60VP from Zeiss. 


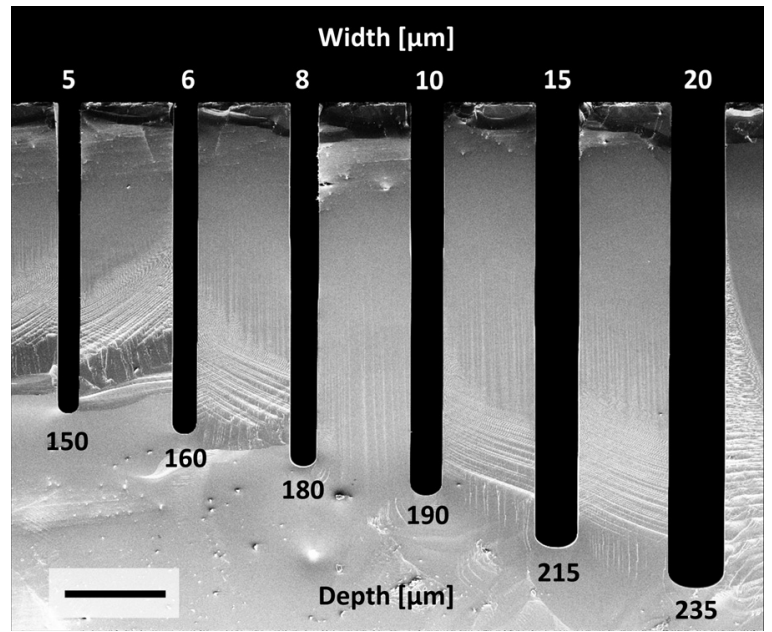

FIG. 3. Scanning electron micrograph of a cross section of deep reactive ion etched trenches. The aspect ratio dependent etching is apparent. The nominal trench widths and the achieved etch depths are indicated in micrometers. The scale bar is $50 \mu \mathrm{m}$.

\section{Optical tests}

The lenses were tested at the beamline ID06 at the European Synchrotron Radiation Facility. A monochromatic X-ray beam was used (Energy $E=17 \mathrm{keV}, \Delta E / E$ $\sim 2 \times 10^{-4}$ ), selected by a $\mathrm{Si}(111)$ double crystal monochromator. At a distance of $55 \mathrm{~m}$ away from the source, the beam was spatially limited by horizontal and vertical slits. The silicon lens was mounted $\sim 0.5 \mathrm{~m}$ downstream the slits for vertical focusing. The transmitted beam was detected by a scintillator screen coupled to a FReLoN CCD camera by microscope optics, giving an effective spatial resolution of $1.4 \mu \mathrm{m}$. The spot size was measured by scanning a straight, absorbing sample (referred to here as a knife) through the focused $\mathrm{X}$-ray beam and recording the integrated beam intensity on the CCD.

\section{RESULTS AND DISCUSSION}

\section{A. DRIE utilizing sacrificial structures}

Figure 3 shows a cross section of trenches after DRIE, the thermal oxidation steps and etching in bHF. The nominal trench widths widened due to silicon consumption, effectively removing the scallops inherent to DRIE. No mask undercut or notable surface defects were observed prior to surface smoothening. ARDE is apparent, and close inspection of the SEM reveals a slight positive tapering ranging from $\alpha \sim 90.4^{\circ}(t=5 \mu \mathrm{m})$ to $\alpha \sim 90.2^{\circ}(t=20 \mu \mathrm{m})$. Hence, profile control is possible by dimensioning the widths of trenches, albeit at the cost of reducing the etch rate. Although not pursued in the current study, profile control with further precision may be possible by fine tuning the etch parameters and consulting the relevant literature. ${ }^{54-59}$

Figures 4(a) and 4(b) show etched large square fields ( $p=5 \mu \mathrm{m}, s=7 \mu \mathrm{m}$ ) before and after removal of the sacrificial structures, respectively. The sacrificial structures partially collapsed during the wafer cleaning and $\mathrm{SiO}_{2}$ etching after DRIE, but were completely removed from the wafer surface and structures. The etch depth is $240 \mu \mathrm{m}$ at the center of the field. At the cleared sidewall, regular vertical striations are visible, originating from pillars that locally influenced the etching conditions. The bottom of the field is shaped by corrugations from pillars whose bases were not completely oxidized. Pillars closest to the sidewall leave larger residues, suggesting a slight increase of the wall-pillar spacing in the

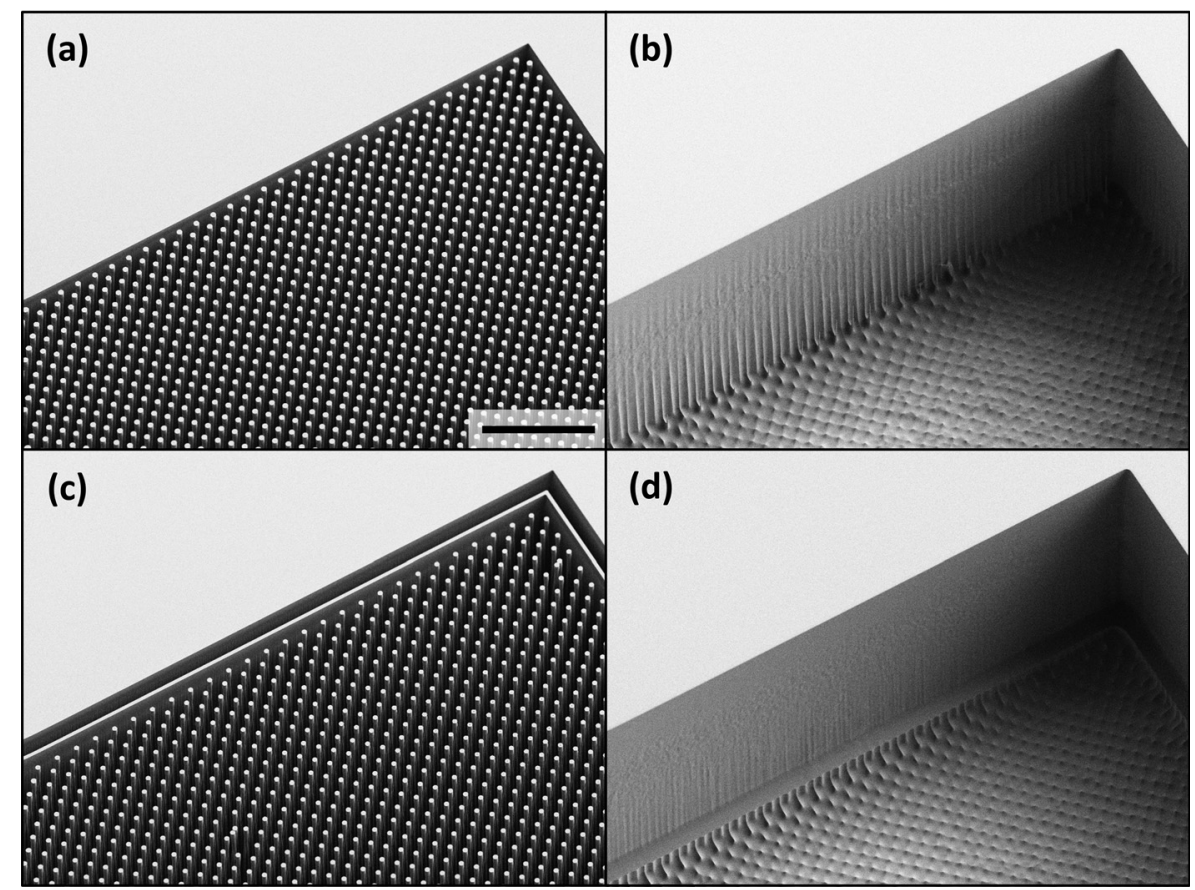

FIG. 4. (a)-(d) Scanning electron micrographs of corners of $1.5 \times 1.5 \mathrm{~mm}^{2}$ deep reactive ion etched test fields before (a) and (c) and after (b) and (d) removal of sacrificial structures. Vertical marks on the sidewalls are apparent in (b), while being absent in (d) where a guarding wall was used. The scale bar is $100 \mu \mathrm{m}$ and the view tilt angle is $30^{\circ}$. 


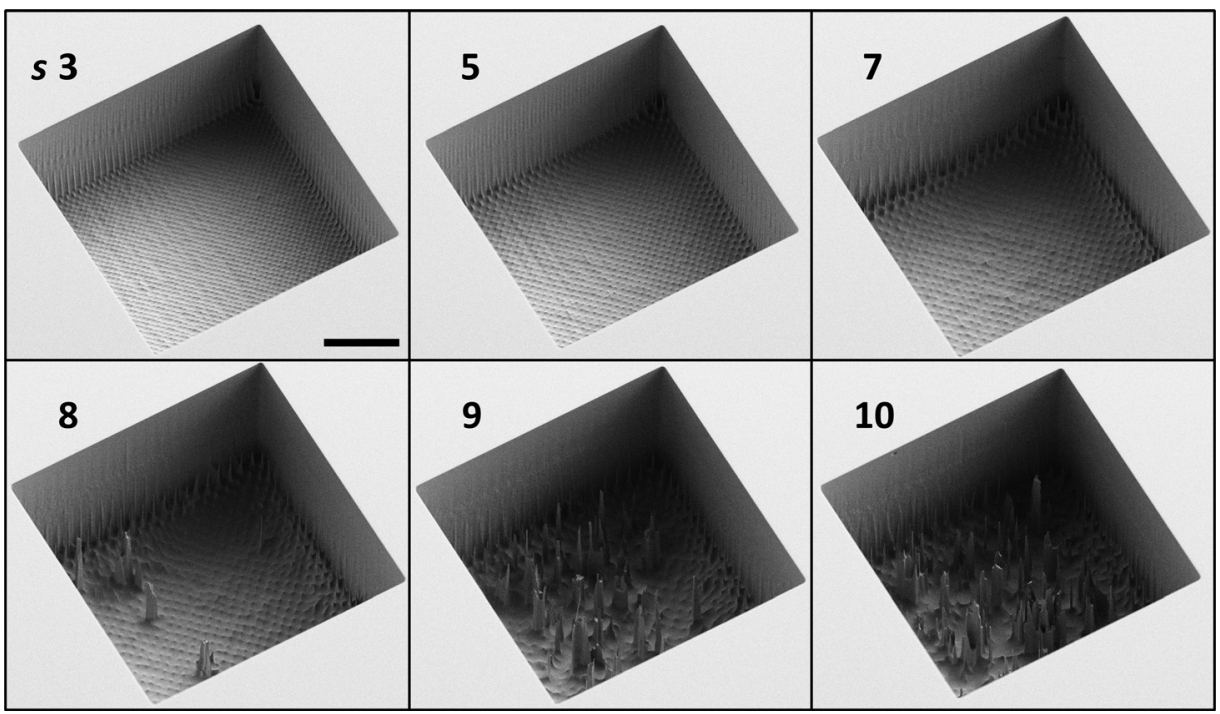

FIG. 5. Effect of varying the pillar spacing: Scanning electron micrographs of small fields after deep reactive ion etching and removal of sacrificial structures. The diameter of the pillars was $4 \mu \mathrm{m}$ and the pillar spacing $s$ of each field is indicated in micron. The scale bar is $100 \mu \mathrm{m}$ and the view tilt angle is $30^{\circ}$.

future. When a trench and a guarding wall were used $(w=4 \mu \mathrm{m}, t=15 \mu \mathrm{m})$, sidewall defects were largely reduced [Figs. 4(c) and 4(d)].

The effect of the pillar spacing on their integrity was investigated (cf. Fig. 5). Larger spacing resulted in faster vertical etching, but more pronounced lateral etching, and at a certain point caused the collapse of pillars during DRIE. The collapse of small-diameter pillars was more likely and once it happened, uncontrolled etching occurred, leaving large residues inside the structures. At the onset of structural collapse, the aspect ratio of pillars was $67(p=4 \mu \mathrm{m}$, $s=7 \mu \mathrm{m})$. Notably, the collapse of pillars was more likely in the small fields, indicating a more effective etching of areas with less exposed silicon, which is consistent with the microloading effect. ${ }^{46-48}$

Figure 6(a) illustrates how the etch depth (and hence etch rate) of areas filled with pillars depends on the pillar spacing. This dependence is similar to ARDE encountered in the case of trenches or holes with varying widths or diameters, respectively. Evidence of microloading is also apparent when comparing etch depths of differently sized fields with identical dimensions of sacrificial pillars [Fig. 6(a), $p=5 \mu \mathrm{m}]$. Generally, the etch depths of large fields are up to $3 \%$ smaller than those from smaller fields.

The interdependency of the spacing and diameters of the pillars affecting the etch depth of the large fields was investigated. In Fig. 6(b), the etch depth is color encoded in an interpolated surface plot. A local etch load of the corresponding field was assigned to each $p$-s-combination and drawn on the abscissa. Similarly, a silicon area per masking dot can be assigned and its square-root is drawn on the ordinate. Isolines corresponding to the etch depths of trenches with certain widths are included. This diagram facilitates finding the optimum $t-p$-s-combination for obtaining a certain etch depth, while maximizing etch rate and minimizing $p$, which reduces the amount of necessary thermal oxidation for structure removal. It also sheds light onto how a certain trench may be associated with a $p$-s-combination and a local etch load, which is worth a separate, more detailed analysis.

Figure 7 shows fields with varying $t-w-p$-s-combinations. Clearly, the etch depths at the sidewalls and the insides of structures could be readily controlled by the proper dimensioning of sacrificial structures. The interior could be etched deeper than the perimeter (e.g., $t=5 \mu \mathrm{m}, \quad w=4 \mu \mathrm{m}$,
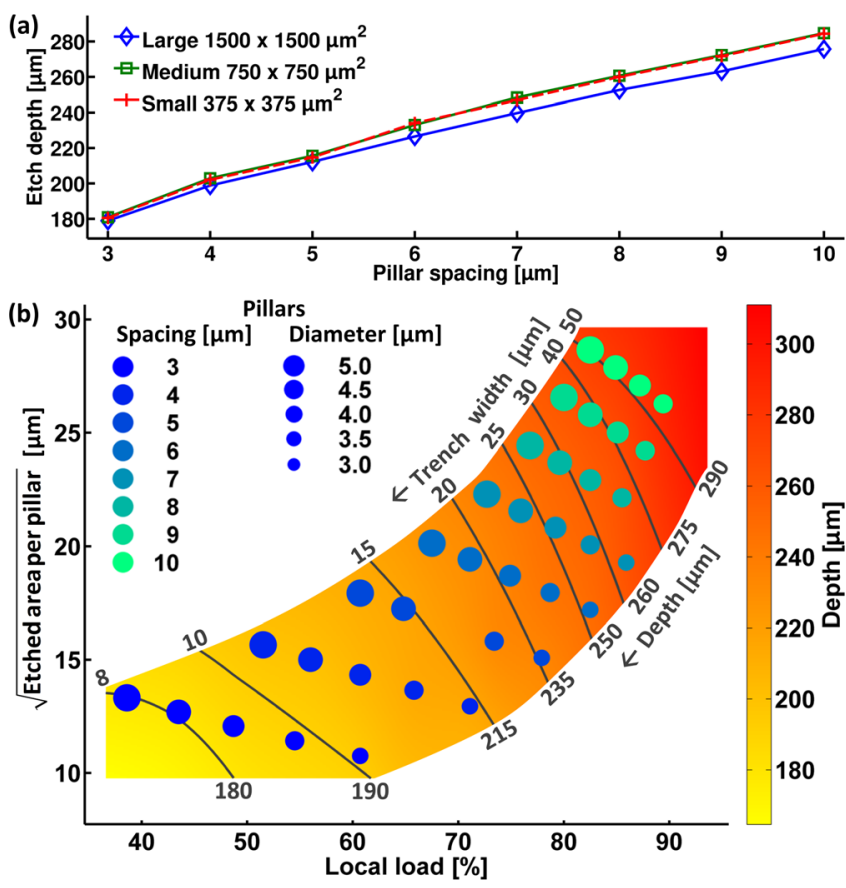

FIG. 6. (Color online) (a) Dependence of the etch depths on the spacing $s$ between pillars. The pillar diameter $p$ is left constant at $5 \mu \mathrm{m}$. (b) Dependence of the etch depth of the large fields on the diameter $p$ of the pillars and the spacing $s$ between the pillars. Additionally, the etch depths of trenches with different widths are indicated by isolines. The measuring point with $p=4 \mu \mathrm{m}$ and $s=5 \mu \mathrm{m}$ is missing, because of an error in the mask design. The measuring points with $p=3 \mu \mathrm{m}$ and $s=8-10 \mu \mathrm{m}$ are missing, because the pillars collapsed prior to the completion of the etching process. 


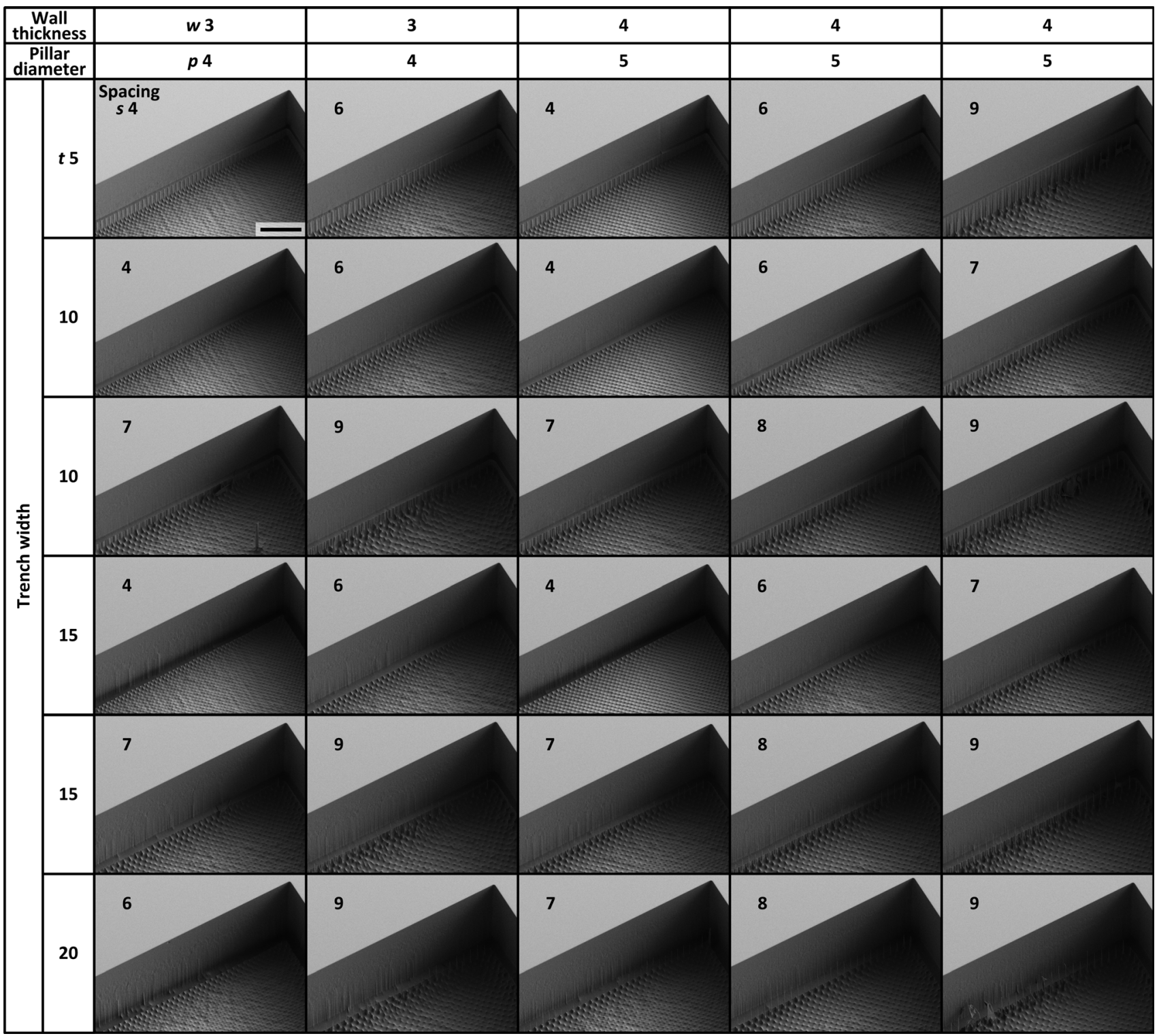

FIG. 7. Scanning electron micrographs of corners of large fields with varying $t-w-p-s$ combinations after deep reactive ion etching and removal of sacrificial structures. The scale bar is $100 \mu \mathrm{m}$ and the view tilt angle is $30^{\circ}$. The unit of all values is $1 \mu \mathrm{m}$.

$p=5 \mu \mathrm{m}$, and $s=9 \mu \mathrm{m})$ and conversely the perimeter could be etched deeper than the interior (e.g., $t=15 \mu \mathrm{m}, w=4 \mu \mathrm{m}$, $p=5 \mu \mathrm{m}, s=4 \mu \mathrm{m})$. Structural defects as, e.g., in the field $(t=10 \mu \mathrm{m}, \quad w=3 \mu \mathrm{m}, \quad p=4 \mu \mathrm{m}, \quad$ and $s=7 \mu \mathrm{m})$ rarely occurred, and in this particular case, the residue in the middle of the field was most likely caused during the lithography. Vertical striations are more pronounced on the sidewalls of fields defined by wider trenches $(t=15$ and $20 \mu \mathrm{m}$, corresponding to $d=215$ and $235 \mu \mathrm{m}$, respectively), than in the case of narrower trenches $(t=5$ and $10 \mu \mathrm{m}$, corresponding to $d=150$ and $190 \mu \mathrm{m}$, respectively). This variation may be attributed to partial breakthrough of the guarding wall, as is evident by a comparison of sidewalls of fields that only differ by the wall thickness. Wall breakthrough, which is more likely for a thin wall $(w=3 \mu \mathrm{m})$ than for a thick wall $(w=4 \mu \mathrm{m})$, causes a partial coalescence of a trench with the pillar-filled area, and hence results in a local change of etching conditions. Arbitrarily shaped multilevel structures are feasible, as previously demonstrated for structures aligned along crystal planes. ${ }^{28}$

\section{B. DRIE of kinoform x-ray lenses}

Sacrificial structures were used in the manufacture of compound kinoform x-ray lenses. Figure 8 shows cross sections of lenses after DRIE, where cleavages were obtained at different positions across the features illustrating the integrity of sacrificial structures and realization of uniform etch depths. The pillars $(p=5 \mu \mathrm{m}$ and $s=7 \mu \mathrm{m})$ have an aspect ratio of $\sim 50$, are intact, but show a slight bowing indicating lateral etching. The guarding wall $(w=4 \mu \mathrm{m})$ is intact, but partial breakthrough is visible. The corners of the steps are sharp at the top $\sim 100 \mu \mathrm{m}$, but slightly positively tapered toward the bottom.

Figure 9(a) shows a top view of a kinoform lenslet after DRIE and Fig. 9(b) after the complete removal of sacrificial 


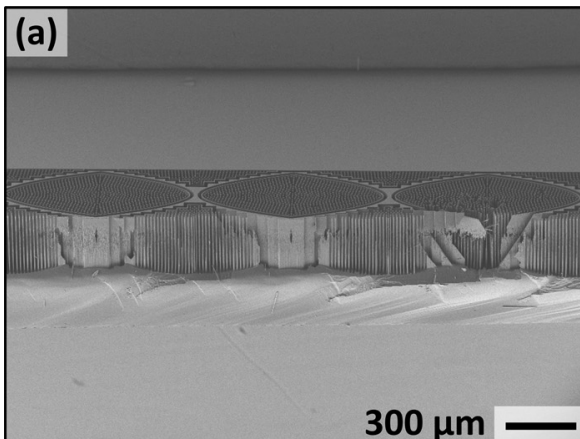

(c)

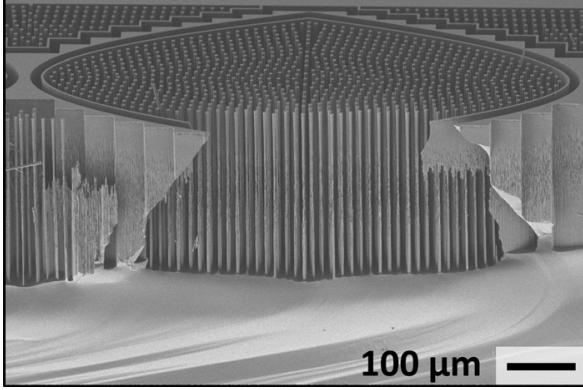

(b)

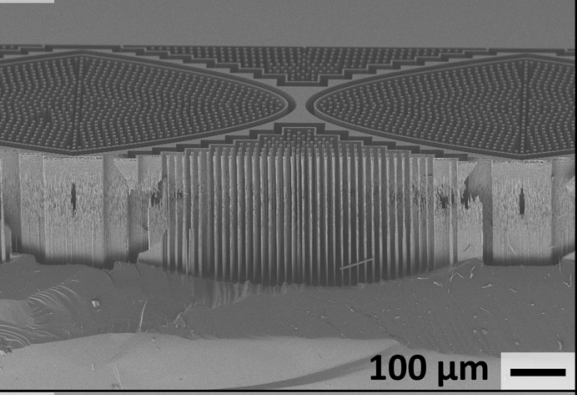

(d)

FIG. 8. Scanning electron micrographs of cross-sections of deep reactive ion etched kinoform x-ray lenses before sacrificial structure removal. (a) Extended view. (b)-(d) Close-ups with different lines of cleavage. The view tilt angle is $60^{\circ}$.

structures by thermal oxidation and bHF etching. The compensation of silicon consumption was effective, resulting in kinoforms close to their nominal dimensions. Figure 9(c) shows a section of the CRL composed of 60 lenslets without any notable defects. No breakthrough occurred at the corners of the steps. The visible bright shades indicate that the silicon is locally thin and that the sidewalls are slightly bowed. A top view of the steps [cf. inset in Fig. 9(c)] reveals sharp

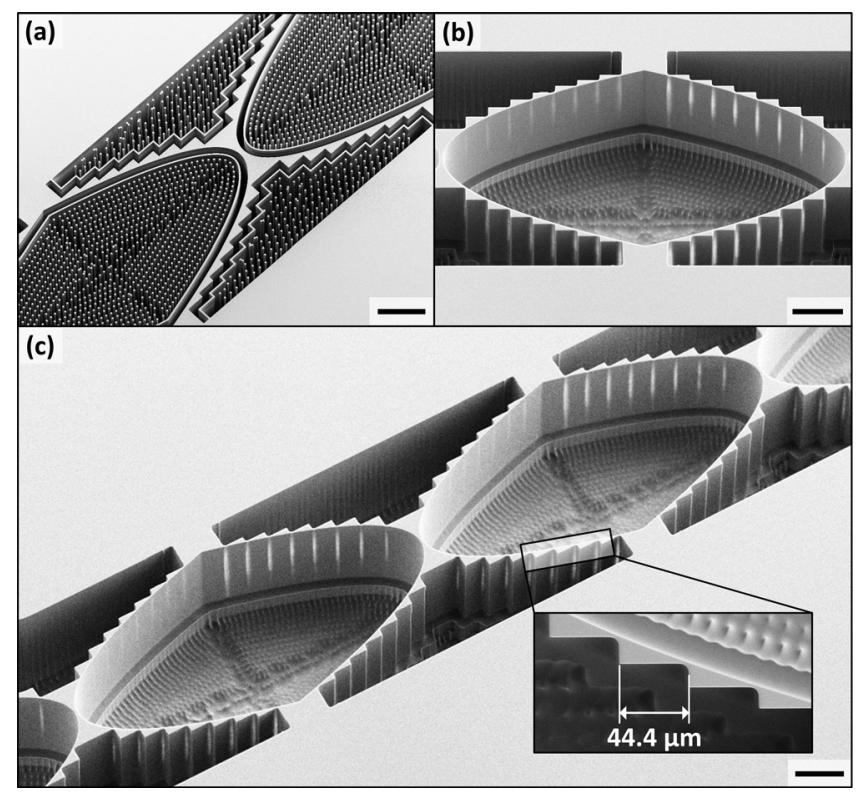

FIG. 9. Scanning electron micrographs of deep reactive ion etched kinoform $\mathrm{X}$-ray lenses before (a) and after (b) and (c) the removal of sacrificial structures. Note the bright vertical stripes in (b) and (c) indicating the thinness of the sidewalls at the step boundaries. All scale bars are $500 \mu \mathrm{m}$ and the view tilt angle is $30^{\circ}$. The inset in (c) shows a top view of the kinoform steps. convex and rounded concave corners, which are due to the physics of the oxidation. ${ }^{60}$ The rounded corners clearly affect the lens shape and will locally cause additional refraction. The length of the kinoform steps is $44.4 \pm 0.7 \mu \mathrm{m}$ and deviates up to $3 \%$ from the nominal value. For optimal focusing and a maximum wavefront distortion of $\lambda / 4$, this deviation should be less than $0.3 \%$. The bridge thickness $b$ is $7.2 \mu \mathrm{m}$. Hence, not enough silicon was consumed relatively to the original design. However, additional thermal oxidation would most likely have caused partial breakthrough of the sidewalls and we accepted these minor shape deviations for an optical test.

\section{Optical performance}

Two types of experiments were performed to test the optical performance. The first sought to determine how different regions across the lens aperture shaped the incoming beam, whereas the second specifically concerned the achieved spot size (i.e., beam waist) as a function of the lens depth. The lenses were aligned for optimal transmission, i.e., parallel to the incoming beam direction, and the detector was placed at twice the focal length $2 f=430 \mathrm{~mm}$ [cf. Fig. 10(a)]. A horizontal slit was adapted to the depth of the lenses $(d=200 \mu \mathrm{m})$ and a vertical slit with an opening of $\sim 5 \mu \mathrm{m}$ was scanned across the aperture of the lens in steps of $2.5 \mu \mathrm{m}$. Figure 10(b) shows the transmitted beam monitored on the CCD as a function of the slit positions, whereas the beam intensity was summed in the direction of the lens depth (see supplementary material ${ }^{61}$ ). The diagonal line indicates correct optical performance of the lens, i.e., rays impinging on a certain position at the lens aperture got refracted, pass 

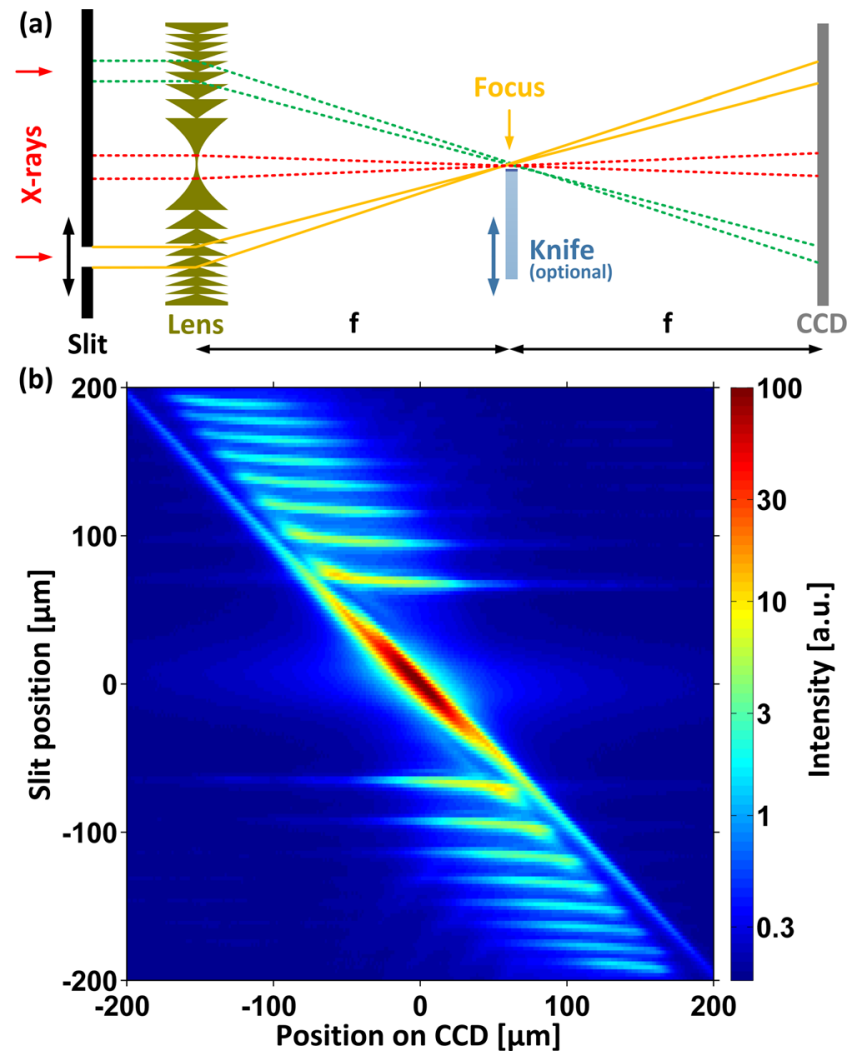

FIG. 10. (Color online) Optical transmission and refractive behavior of the silicon x-ray lenses. (a) Conceptual drawing of the optical setup. A $5 \mu \mathrm{m}$ wide slit was scanned across the lens aperture and the scattered beam recorded with a CCD detector positioned at twice the focal distance from the lens. A knife optionally inserted into the beam path is used for spot size measurements. The lens is shown as a folded kinoform for simplicity. (b) Surface plot of the x-ray intensity on the space resolved CCD. The diagonal line indicates correct refraction of the $\mathrm{x}$-ray beam. While the middle lens section is flawless, the kinoform steps scatter and reflect the beam wildly. Note the logarithmic scale. See supplementary material (Ref. 61).

the focal plane at a common focal position, and strike the detector at their conjugate positions.

The central, $100 \mu \mathrm{m}$-wide region showed flawless optical behavior and a lens transmittance of $21 \%$, in agreement with theoretical expectations. ${ }^{32}$ Optical performance in the regions of the kinoform steps was dominated by nonideal $\mathrm{x}$-ray scattering, i.e., departing from the bright diagonal line of intensity. We attribute this nonideal behavior to successive total external reflection of the refracted beam at the sidewalls of the kinoform steps. Because the lens was composed of multiple elements, the beam converged inside the lens, which was intended to be compensated for by the adiabatic lens design. However, the beam converged faster than expected, which was to some extent caused by an increased focusing power of the lens as a consequence of the incomplete removal of sacrificial silicon. Future lens designs thus need to take potential total reflection into account. The transmission at the kinoform steps was negligible relative to transmission at the central region. A total lens transmittance of $14.3 \%$ was expected, while a transmittance of $7.3 \%$ was measured. The gain in transmission compared to a nonkinoform lens was $1.3 \%$ and generally did not contribute to the focus.
Spot size measurements were performed by inserting an absorbing sample into the light path and taking knife-edge scans [cf. Fig. 10(a)]. Figure 11(a) shows the result from such a scan. Calculating the derivative of the envelope of the raw data yields a full width at half maximum of $430 \mathrm{~nm}$ of the focused $\sim 180 \mu \mathrm{m}$ long line beam. No notable difference in spot size was observed between illuminating the full aperture of the lens or only its central part. Figure 11(b) shows the center of the intensity profile of the transmitted beam. The transmission profile of the aperture is Gaussian with a $1 / \mathrm{e}^{2}$-width of $\sim 60 \mu \mathrm{m}$, but with broad tails originating from the kinoform steps. The gain in photon flux density of the central part was 50 . The uniformity of the beam intensity along the lens depth is $\sim 94 \%$, whereas the slight maximum at a depth of $\sim 45 \mu \mathrm{m}$ is most likely due to the aforementioned sidewall bowing and the cause for the variation at a depth of $\sim 120 \mu$ m remains unknown.

The spatially resolved CCD detector allowed the focusing behavior along the lens depth direction to be measured. Therefore, the beam intensity on the CCD was divided into $50 \mu \mathrm{m}$ long sections, which were analyzed separately. Knifeedge scans were performed at different positions along the optical axis around the focal position to obtain information pertaining to the depth-of-focus [Fig. 11(c)]. Focused beams from individual sections are close to Gaussian in profile. A minimum beam waist of $250 \mathrm{~nm}$ was measured for the top $50 \mu \mathrm{m}$ section, which matches the ideally expected spot size (considering the diffraction limit and source demagnification). Generally, the topmost lens section outperformed the
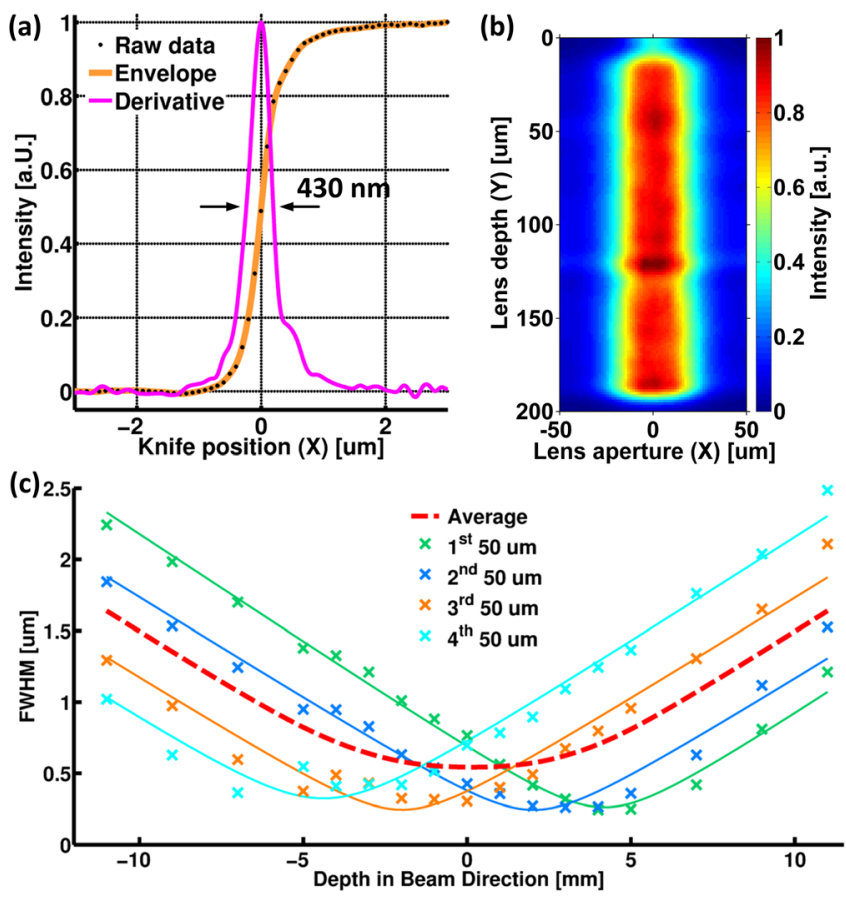

FIG. 11. (Color online) Beam focusing performance of the silicon x-ray lenses. (a) Integrated intensity on the CCD while the knife was scanned through the focal plane of the $\sim 180 \mu \mathrm{m}$ long line beam. (b) CCD image of the projection of the same beam twice the focal length from the exit of the lens. (c) Depth of focus scans and separate analysis of different depths of the lens. The full lines are fits to the function of a Gaussian beam. The average of the individual Gaussian beams is indicated by a dashed line. 
lowermost, and stronger focusing was observed at the bottom section of the lens. This decrease of the focal length from the top to the bottom of the lens can be attributed to a nonuniform shape along its depth. More specifically, the slanted focal plane can be attributed to a steady decrease of $R$ along the depth of a lenslet, corresponding to positively tapered sidewalls $\left(\alpha \approx 90.5^{\circ}\right)$. In order to guarantee a uniform line focus with minimal waist, a future iteration needs to improve the verticality of the sidewalls to $\sim 90 \pm 0.05^{\circ}$. The averaged beam showed a depth of focus $\sim 2 \mathrm{~mm}$, determining the necessary accuracy for sample placement.

The demonstrated $180 \mu \mathrm{m}$-long line beam with a waist of $430 \mathrm{~nm}$ is remarkable and can be contrasted to the performance of similar silicon refractive optics discussed in literature. ${ }^{34-36}$ Although the spot size does not reach $\sim 50 \mathrm{~nm}$, as was previously demonstrated with a $60 \mu \mathrm{m}$ deep etched silicon lens with $\sim 11 \mathrm{~mm}$ focal length, ${ }^{34}$ the lens depth achieved here is three times higher and the focal length of $215 \mathrm{~mm}$ provides ample space for sample surroundings. The over-depth uniformity of our lens was accomplished by the use of sacrificial structures. Notably, lenses manufactured by (rarely available) x-ray lithography of polymers, ${ }^{62,63}$ multiprism lenses (approximating the ideal refracting profile by multiple wedges, made, e.g., by anisotropically wet etched silicon), ${ }^{64}$ or Fresnel zone plates ${ }^{65,66}$ are viable alternatives to silicon x-ray lenses made by DRIE. Our attempt to double the lens transmittance by a kinoform design failed due to our underestimation of the convergence of the beam inside the lens. Recent developments of kinoform x-ray lenses seem to concentrate on the fabrication of single plano-concave lens elements with relatively small radii of curvature, although some compound lenses are reported as well. ${ }^{41-45,67}$ Due to the parabolic profile, the steps of such lenses reach high aspect ratios very quickly at their apertures and the demonstrated utilization of sacrificial structures for profile control may facilitate increasing the heights of future silicon kinoform optics.

\section{CONCLUSIONS}

Sacrificial structures in the form of guarding walls and pillars were investigated for their usefulness in assisting sidewall profile control of complex deep reactive ion etched structures. A guarding wall proved to be necessary for achieving smooth sidewalls. The effects of critical dimensional parameters such as wall thicknesses, pillar diameters, and pillar spacing on the etching were systematically studied. The etch depth of sacrificial pillars can be controlled and adapted to the etch depth of shape-defining trenches by adjusting the spacing between pillars. A maximal aspect ratio of $\sim 60$ of the final pillars was found to guarantee the integrity of sacrificial structures. Narrower trenches yielded smoother sidewalls, but also lower etch rates. Structural units of sizes between $375 \times 375$ and $1500 \times 1500 \mu \mathrm{m}^{2}$ did only show minor differences in etch depths. Sacrificial structures were completely removed by thermal oxidation and selective etching in hydrofluoric acid, leaving no residues if their integrity was maintained during DRIE.
The design and manufacturing strategy was applied on the realization of kinoform x-ray lenses. Their test showed correct refractive behavior, but also large detrimental scattering, which annihilated the potential merit of doubling the transmission compared to a standard x-ray lens. However, the use of sacrificial structures generally allowed the focusing of hard x-rays into a $180 \mu$ m-long line with a width of $430 \mathrm{~nm}$. This beam will be of great use for performing x-ray microscopy of condensed materials. ${ }^{68}$

\section{ACKNOWLEDGMENTS}

H. F. Poulsen acknowledges an ERC Advanced grant, dTXM. H. Simons acknowledges support from a DFF-FTP individual postdoc grant. O. Hansen acknowledges support from The Danish National Research Foundation's Center for Individual Nanoparticle Functionality, CINF (DNRF54). The authors thank ESRF for provision of beamtime and DANSCATT for support. F.S. thanks Henri Jansen for fruitful discussions.

${ }^{1}$ F. Laermer and A. Urban, Microelectron. Eng. 67-68, 349 (2003).

${ }^{2}$ H. V. Jansen, M. J. de Boer, S. Unnikrishnan, M. C. Louwerse, and M. C. Elwenspoek, J. Micromech. Microeng. 19, 033001 (2009).

${ }^{3}$ B. Wu, A. Kumar, and S. Pamarthy, J. Appl. Phys. 108, 051101 (2010).

${ }^{4}$ R. A. Gottscho, J. Vac. Sci. Technol. B Microelectron. Nanometer Struct. 10, 2133 (1992).

${ }^{5}$ H. Jansen, M. de Boer, R. Wiegerink, N. Tas, E. Smulders, C. Neagu, and M. Elwenspoek, Microelectron. Eng. 35, 45 (1997).

${ }^{6}$ C. W. Jurgensen, J. Vac. Sci. Technol. B 7, 1488 (1989).

${ }^{7}$ J. Liu, G. L. Huppert, and H. H. Sawin, J. Appl. Phys. 68, 3916 (1990).

${ }^{8}$ D. J. Economou, J. Electrochem. Soc. 135, 941 (1988).

${ }^{9}$ S. G. Ingram, J. Appl. Phys. 68, 500 (1990).

${ }^{10}$ J. C. Arnold and H. H. Sawin, J. Appl. Phys. 70, 5314 (1991).

${ }^{11}$ R. J. Davis, Appl. Phys. Lett. 59, 1717 (1991).

${ }^{12}$ J. Kiihamaüki and S. Franssila, J. Vac. Sci. Technol. A 17, 2280 (1999).

${ }^{13}$ M. Boufnichel, S. Aachboun, F. Grangeon, P. Lefaucheux, and P. Ranson, J. Vac. Sci. Technol. B 20, 1508 (2002).

${ }^{14}$ M. Boufnichel, S. Aachboun, P. Lefaucheux, and P. Ranson, J. Vac. Sci. Technol. B 21, 267 (2003).

${ }^{15}$ E. S. G. Shaqfeh and C. W. Jurgensen, J. Appl. Phys. 66, 4664 (1989).

${ }^{16}$ S. L. Lai, D. Johnson, and R. Westerman, J. Vac. Sci. Technol. A 24, 1283 (2006).

${ }^{17}$ R. Barnett, D. Thomas, Y. Song, D. Tossell, T. Barrass, and O. Ansell, Proceedings of the 60th Electronic Components Technology Conference (IEEE, 2010), pp. 1056-1059.

${ }^{18}$ N. C. H. Le, D. V. Dao, R. Yokokawa, J. C. Wells, and S. Sugiyama, Microsyst. Technol. 15, 1845 (2009).

${ }^{19}$ R. K. Chutani, M. Hasegawa, V. Maurice, N. Passilly, and C. Gorecki, Sens. Actuators A 208, 66 (2014).

${ }^{20}$ F. Stöhr, J. Wright, H. Simons, J. Michael-Lindhard, J. Hübner, F. Jensen, O. Hansen, and H. F. Poulsen, "Optimizing shape uniformity and increasing structure heights of deep reactive ion etched silicon X-ray lenses," J. Micromech. Microeng. (submitted).

${ }^{21}$ R. Agarwal, S. Samson, and S. Bhansali, J. Micromech. Microeng. 17, 26 (2007).

${ }^{22}$ S. Seok, B. Lee, J. Kim, H. Kim, and K. Chun, J. Micromech. Microeng. 15, 1791 (2005).

${ }^{23}$ P. T. Docker, P. K. Kinnell, and M. C. L. Ward, J. Micromech. Microeng. 14, 941 (2004).

${ }^{24}$ B. E. Volland, H. Heerlein, I. Kostic, and I. W. Rangelow, Microelectron. Eng. 57-58, 641 (2001).

${ }^{25}$ F. Marty, L. Rousseau, B. Saadany, B. Mercier, O. Français, Y. Mita, and T. Bourouina, Microelectron. J. 36, 673 (2005).

${ }^{26}$ Y. Mita, M. Kubota, T. Harada, F. Marty, B. Saadany, T. Bourouina, and T. Shibata, J. Micromech. Microeng. 16, 135 (2006).

${ }^{27}$ T. Ikehara and R. Maeda, Microsyst. Technol. 12, 98 (2005). 
${ }^{28}$ J. Kiihamäki, H. Kattelus, J. Karttunen, and S. Franssila, Sens. Actuators 82, 234 (2000).

${ }^{29}$ G. E. Ice, J. D. Budai, and J. W. L. Pang, Science 334, 1234 (2011).

${ }^{30}$ A. Snigirev, V. Kohn, I. Snigireva, and B. Lengeler, Nature 384, 49 (1996).

${ }^{31}$ V. V. Aristov, M. V. Grigoriev, S. M. Kuznetsov, L. G. Shabelnikov, V. A. Yunkin, M. Hoffmann, and E. Voges, Opt. Commun. 177, 33 (2000).

${ }^{32}$ B. Lengeler et al., Nucl. Instrum. Methods Phys. Res. Sect. A 467-468, 944 (2001).

${ }^{33}$ V. Nazmov, E. Reznikova, J. Mohr, A. Snigirev, I. Snigireva, S. Achenbach, and V. Saile, Microsyst. Technol. 10, 716 (2004).

${ }^{34}$ C. G. Schroer et al., Appl. Phys. Lett. 87, 124103 (2005).

${ }^{35}$ O. Kurapova, B. Lengeler, C. G. Schroer, M. Küchler, T. Gessner, and A. van der Hart, J. Vac. Sci. Technol. B 25, 1626 (2007).

${ }^{36}$ A. Snigirev, I. Snigireva, M. Grigoriev, V. Yunkin, M. Di Michiel, S. Kuznetsov, and G. Vaughan, Proc. SPIE 6705, 670506 (2007).

${ }^{37}$ F. Seiboth et al., Appl. Phys. Lett. 105, 131110 (2014).

${ }^{38}$ F. Stöhr, H. Simons, A. C. Jakobsen, C. H. Nielsen, J. Michael-Lindhard, F. Jensen, H. F. Poulsen, O. Hansen, and J. Hübner, "Injection molded polymeric hard X-ray lenses," Opt. Mater. Express (submitted).

${ }^{39}$ L. B. Lesem, P. M. Hirsch, and J. A. Jordan, IBM J. Res. Dev. 13, 150 (1969).

${ }^{40}$ K. Evans-Lutterodt et al., Opt. Express 11, 919 (2003).

${ }^{41}$ A. Stein, K. Evans-Lutterodt, N. Bozovic, and A. Taylor, J. Vac. Sci. Technol. B 26, 122 (2008).

${ }^{42}$ L. Alianelli, K. J. S. Sawhney, R. Barrett, I. Pape, A. Malik, and M. C. Wilson, Opt. Express 19, 11120 (2011).

${ }^{43}$ M. K. Tiwari, L. Alianelli, I. P. Dolbnya, and K. J. S. Sawhney, J. Synchrotron Radiat. 17, 237 (2010).

${ }^{44}$ A. R. Sandy, S. Narayanan, M. Sprung, J.-D. Su, K. Evans-Lutterodt, A. F. Isakovic, and A. Stein, J. Synchrotron Radiat. 17, 314 (2010).

${ }^{45}$ S. D. Shastri, K. Evans-Lutterodt, R. L. Sheffield, A. Stein, M. Metzler, and P. Kenesei, Proc. SPIE 9207, 920704 (2014).

${ }^{46}$ C. J. Mogab, J. Electrochem. Soc. 124, 1262 (1977).
${ }^{47}$ J. Karttunen, J. Kiihamäki, and S. Franssila, Proc. SPIE 4174, 90 (2000).

${ }^{48} \mathrm{~S}$. Jensen and O. Hansen, Proc. SPIE 5342, 111 (2004).

${ }^{49}$ C. Schroer and B. Lengeler, Phys. Rev. Lett. 94, 054802 (2005).

${ }^{50}$ Z. Chen, H. Xie, B. Deng, and G. Du, Chin. Opt. Lett. 12, 123401 (2014).

${ }^{51}$ P. Persson and G. Strang, SIAM Rev. 46, 329 (2004).

${ }^{52}$ W. H. Juan, J. Vac. Sci. Technol. B 14, 4080 (1996).

${ }^{53}$ F. Stöhr, J. Michael-Lindhard, H. Simons, H. F. Poulsen, J. Hübner, O. Hansen, J. Garnaes, and F. Jensen, Microelectron. Eng. 141, 6 (2015).

${ }^{54}$ A. A. Ayón, J. Electrochem. Soc. 146, 2730 (1999).

${ }^{55}$ M. A. Blauw, T. Zijlstra, and E. van der Drift, J. Vac. Sci. Technol. B 19, 2930 (2001)

${ }^{56}$ M. A. Blauw, G. Craciun, W. G. Sloof, P. J. French, and E. van der Drift, J. Vac. Sci. Technol. B 20, 3106 (2002).

${ }^{57}$ C. J. D. Craigie, T. Sheehan, V. N. Johnson, S. L. Burkett, A. J. Moll, and W. B. Knowlton, J. Vac. Sci. Technol. B 20, 2229 (2002).

${ }^{58}$ R. Abdolvand and F. Ayazi, Sens. Actuators A Phys. 144, 109 (2008).

${ }^{59}$ J. Ohara, Y. Takeuchi, and K. Sato, J. Micromech. Microeng. 19, 095022 (2009).

${ }^{60}$ D.-B. Kao, J. P. McVittie, W. D. Nix, and K. C. Saraswat, IEEE Trans. Electron Devices 34, 1008 (1987).

${ }^{61}$ See supplementary material at http://dx.doi.org/10.1116/1.4931622 for a sequence of two dimensional radiographs.

${ }^{62}$ V. Nazmov, L. Shabel'nikov, F.-J. Pantenburg, J. Mohr, E. Reznikova, A. Snigirev, I. Snigireva, S. Kouznetsov, and M. DiMichiel, Nucl. Instrum. Methods Phys. Res. Sect. B 217, 409 (2004).

${ }^{63}$ V. Nazmov, E. Reznikova, J. Mohr, V. Saile, L. Vincze, B. Vekemans, S. Bohic, and A. Somogyi, J. Micromech. Microeng. 21, 015020 (2011).

${ }^{64}$ B. Cederström, M. Lundqvist, and C. Ribbing, Appl. Phys. Lett. 81, 1399 (2002).

${ }^{65}$ P. Karvinen et al., Opt. Express 22, 16676 (2014).

${ }^{66}$ I. Mohacsi et al., Opt. Express 23, 776 (2015).

${ }^{67}$ K. Evans-Lutterodt, A. Stein, J. Ablett, N. Bozovic, A. Taylor, and D. Tennant, Phys. Rev. Lett. 99, 134801 (2007).

${ }^{68} \mathrm{H}$. Simons et al., Nat. Commun. 6, 6098 (2015). 